\title{
A disciplina de História no Paraná: compêndios escolares, ensino secundário e formação de elites intelectuais
}

\section{History subject in Parana: school textbooks, secondary education and training of intellectual elites}

\author{
Maria Aparecida Leopoldino Toledo ${ }^{1}$
}

\begin{abstract}
RESUMO
$\mathrm{O}$ artigo consiste em um estudo sobre a constituição da disciplina de História no Paraná. Percorre a formação desse campo disciplinar no trajeto de afirmação da instituição secundária no contexto político e cultural da então Província paranaense de meados do século XIX. A configuração da História escolar é analisada por meio dos compêndios escolares adotados à época e considera suas implicações para a formação de uma elite intelectual que se preparava, por intermédio dos cursos secundários, para assumir cargos na burocracia do Estado no período em que a sociedade brasileira transita do Império para a República como forma de governo.

Palavras-chave: ensino de História; Paraná; ensino secundário.
\end{abstract}

\begin{abstract}
This paper consists of a study on the establishment of the History subject in the state of Parana, Brazil. It examines the structure of this disciplinary field along the path of the assertion of the secondary school in the political and cultural context of the former Province of Parana during the mid-19th Century. The configuration of History teaching is analyzed through the textbooks adopted at that time and considers its implications for the development of an intellectual elite, that was being prepared, by means of the secondary courses, to take positions in the state bureaucracy during the period in which Brazilian society transited from the Empire to the Republic as a form of government.

Keywords: History teaching; Parana; secondary education.
\end{abstract}

1 Professora do Departamento de Teoria e Prática da Educação . Área: ensino de História, Doutorado em História da Educação da Universidade Estadual de Maringá - Brasil. 


\section{Introdução}

Diversos autores têm sublinhado a função social da História e de uma significativa parcela da elite intelectual na formação da memória e da identidade nacional, quando dos processos de formação dos Estados Nacionais nos séculos XVIII e XIX no cenário europeu. Nos últimos anos as pesquisas sobre a história da disciplina vêm, por sua vez, confirmando o fato de que a educação secundária foi a que, inicialmente e mais detidamente, se debruçou sobre o passado da nação, derivando dela a formação de uma elite intelectual conhecedora do passado nacional; num momento em que os conceitos de nação, pátria e povo compunham a idéia de Estado nacional.

No Brasil, por intermédio do ensino secundário, é possível verificar como a disciplina de História contribuiu significativamente para legitimar a independência do Estado brasileiro e sua permanência histórica, bem como para forjar a coesão nacional a partir do século XIX (MATTOS, 1987). No contexto político marcado pela dinâmica e necessidade de definir o nascente Estado nacional brasileiro, não surpreende que a história ensinada tenha, sobretudo, estimulado um sentido de unidade política no campo das questões educacionais seguramente por intermédio dos cursos secundários.

O Colégio Pedro II, como instituição modelar no período imperial e nas décadas iniciais da República, difundiu um padrão de ensino e de historiografia didática para as províncias nacionais vincada no ideário da formação da elite cultural e política da sociedade imperial. Por meio dos exames de preparatórios $^{2}$, política que permitia a equiparação dos programas de ensino dos Liceus em todo o estado nacional no período imperial, tal instituição marcou a história do secundário brasileiro e da formação das elites imperiais no Brasil.

Por certo que o prestígio do Colégio Pedro II como lugar social mantevese quando da instauração da República e das novas exigências sócioculturais de um Estado-nação que os membros da classe senhorial queriam construir, orientando os programas de ensino para a cadeira de História nas províncias do país. No entanto, ressalta-se que, nesse trajeto de constituição do ensino secundário, diferentes propostas para o ensino de História se realizavam nas instituições brasileiras na formação dos letrados.

2 Os exames, regulamentados e fiscalizados pelo governo imperial, durante muito tempo foram apenas realizados na Corte, para onde se dirigiam os candidatos de todas as províncias do país. De responsabilidade do Ministério do Império, que nomeava a Banca de Exames e determinava a lista das matérias que os candidatos deveriam comprovar conhecimentos. Sobre o assunto ver: Silva (1959); Haidar, (1972), Gasparello, (2004). 
Em se tratando do Paraná, no cenário político educacional de fins do século XIX, revelam-se particularidades em relação ao movimento que ocorreria, por exemplo, no colégio da Corte. A adoção do compêndio Lições de História do paranaense Dario Persiano de Castro Vellozo (1869-1937) e sua atuação na cadeira de História Universal no Ginásio Paranaense, de 1898 a 1930, marcaram um período de relativa singularidade na história da disciplina.

Verificou-se que a construção do campo disciplinar da História, na instituição de ensino secundário na província paranaense, relacionou-se com as circunstâncias políticas em que vivia o Paraná. O ensino de História instituído, embora na esteira do que ocorria no colégio da corte, organiza-se por intermédio de conteúdos político, cujo sentido expressa um modo de vivenciar as novas experiências políticas e culturais vividas pela elite intelectual paranaense na conjuntura social de fins do século XIX. Singularidade que, mais do que marcar diferenças com o que ocorria no Colégio Pedro II, marcou um período de se compreender a história e seu ensino, bem como a produção de documentos relevantes para o conhecimento do passado nacional.

É desse movimento que trata o texto. Seu objetivo é contribuir para se pensar a historicidade da formação da disciplina no Brasil considerando as peculiaridades provinciais brasileiras.

\title{
Ensino secundário e elites: o nascedouro da disciplina no Paraná
}

\begin{abstract}
[...] o ensino secundário deve ter por base os estudos literários, que engrandecem a esfera do pensamento, inspiram as ideias e os sentimentos generosos, e são indispensáveis à educação moral de uma nação. (Bento Fernandes de Barros, 1870, grifo meu).
\end{abstract}

O relatório do então inspetor geral de ensino sinaliza para as circunstâncias nas quais o ensino de História desenvolveu-se no Paraná, em fins dos anos de 1870, por meio do ensino secundário. No final do século XIX, status, riqueza e influência política enfeixavam-se em poucas mãos não só na cidade do Rio de Janeiro, mas também nas províncias. No Paraná, quando a capital integrava-se ao mundo das letras, da escrita e das artes, estima-se uma população total correspondente a um montante de 126.722 habitantes, somando-se a ela o contingente de imigrantes que nela vivia há décadas e os escravos que foram 
sendo alforriados. De 1800 a 1900, viu-se crescer o percentual da população branca em detrimento das demais ${ }^{3}$.

Desse componente social, poucos participavam do círculo de letrados do período. Fruto de uma situação em que o domínio das famílias tradicionalmente ligadas a um "modelo fundiário" de produção rural da erva-mate significou, sobretudo, um padrão de continuidade de poder local mais fechado ao ingresso de homens pobres livres e de imigrantes na política regional. Isso teria levado à permanência de grupos sociais de estrutura fundiária no controle político e no processo de urbanização. Em interessante trabalho sobre a genealogia da classe dominante no Paraná, Oliveira (2001, p. 66) informa:

Basta analisarmos as genealogias das familias que estiveram à frente dessas atividades econômicas. [...] Há uma conexão familiar entre as atividades mineradoras de Domingos Cardoso de Lima com as grandes famílias ervateiras do século XIX: os Antonio Ricardo dos Santos, os Modesto Gonçalves Cordeiro, os Nascimento, os Loyola e os Miró. (grifo meu).

Dessas linhagens familiares saíam, no decorrer do século XIX, os jovens paranaenses aspirantes aos cargos públicos ou simplesmente ao título de doutor. Pequeno percentual da população livre preferia seguir seus estudos na Corte, então, logo abandonava a Província para se dirigir, geralmente, aos cursos do Colégio Pedro II e para a Faculdade de Direito em São Paulo. Na realidade, como ocorria na sociedade brasileira do período, no Paraná, o funcionalismo dos setores públicos foi ocupado pelos homens de letras que cursavam o ensino secundário.

Tratava-se de um conjunto de agentes sociais - ou seja, participantes do fechado círculo das elites educadas - que buscavam, em sua maioria, qualificação para os quadros jurídicos, médicos, militares e cargos na burocracia do Estado. Esses motivos fariam com que o curso de preparatórios se tornasse o mais procurado por longo período e aquelas formações as mais disputadas para a entrada nos cursos superiores. No século XIX, ter um curso superior em uma Faculdade de Direito, por exemplo, era a certeza de pertencer ao quadro intelectual da "boa sociedade"4 que no período do Império estava centralizada nas mãos de proprietários rurais.

3 Ver: Westphalen (2002, Vol.1)

4 Conceito utilizado por Mattos (1987) para caracterizar as elites sociais brasileiras do Império. 
Esse foi também um dos aspectos que ligava a elite paranaense lusobrasileira, em sua maioria, ao projeto civilizador das elites imperiais, de tal modo que foram suas visões de sociedade que forjaram os encaminhamentos administrativos e sociais da nova Província, sempre no sentido de somar-se à consolidação do Estado Imperial ou como disse Moreira (1933, p. 9) “o desenvolvimento deste pedaço do Império".

O curso secundário provincial foi definido, portanto, por uma elite cuja prática de aquisição cultural, por intermédio escolar, se realizava naquela modalidade de ensino. O Liceu de Curitiba, criado em 1846, pela Lei Paulista n.33, se efetiva como uma instituição de curso secundário a partir de 1858. Nesse ano, alunos prestaram exames para avançar nas classes marcando os primeiros movimentos da instituição após a autonomia provincial.

Seguindo o livro de atas de exames do Liceu, verifica-se que pelo Regulamento de 10 de julho de 1858 a instituição paranaense estava composta das cadeiras abaixo representadas na lista dos exames:

RELAÇÃO DOS ALUNOS E DAS CADEIRAS A QUE PRESTARAM, NOS EXAMES DE 1858 A 1861

\begin{tabular}{|l|l|c|}
\hline \multicolumn{1}{|c|}{ Aluno } & \multicolumn{1}{|c|}{ Exames da 5 classe } & Ano \\
\hline $\begin{array}{l}\text { Joaquim Silveira da Mota } \\
\text { Generoso Marques dos Santos } \\
\text { Francisco Alvez Guimarães }\end{array}$ & $\begin{array}{l}\text { Grammatica philosophica } \\
\text { História sagrada, no velho } \\
\text { testamento; } \\
\text { Grammatica Latina e traducção } \\
\text { de pedaços } \\
\text { Grammatica franceza, com } \\
\text { traducção em prosa }\end{array}$ & 1858 \\
\hline $\begin{array}{l}\text { Euzébio da Gama Silveira Mota } \\
\text { Brasilio Itibiré da Cunha } \\
\text { Julio d'Oliveira Ribas Franco } \\
\text { Adolfo d'Oliveira Ribas Franco } \\
\text { Francisco Chaves dos Reis } \\
\text { Lisboa }\end{array}$ & $\begin{array}{l}\text { Grammatica philosophica } \\
\text { História sagrada, no velho } \\
\text { testamento; } \\
\text { Grammatica Latina e traducção } \\
\text { de pedaços } \\
\text { Grammatica franceza, com } \\
\text { traducção em prosa }\end{array}$ & 1859 \\
\hline & Exames da 4a classe & 1859 \\
\hline
\end{tabular}




\begin{tabular}{|c|c|c|}
\hline Aluno & Exames da $5^{\text {a }}$ classe & Ano \\
\hline $\begin{array}{l}\text { Generoso Marques dos Santos } \\
\text { Francisco Alves Guimarães }\end{array}$ & $\begin{array}{l}\text { História Sagrada, novo } \\
\text { testamento; } \\
\text { História Universal e Antiga; } \\
\text { Geografia phisica; } \\
\text { Arithmetica; Latim; } \\
\text { Tradução de períodos curtos de } \\
\text { regência grammatical; Francez, } \\
\text { traducção e exercício de } \\
\text { conversão; Inglez; grammatica } \\
\text { e tradução de pedaços; } \\
\text { Botânica }\end{array}$ & \\
\hline $\begin{array}{l}\text { Euzébio da Gama Silveira da } \\
\text { Mota } \\
\text { Francisco Xavier dos Reis } \\
\text { Lisboa } \\
\text { Brasilio Itibiré da Cunha }\end{array}$ & $\begin{array}{l}\text { História Sagrada, novo } \\
\text { testamento; } \\
\text { História Universal e Antiga; } \\
\text { Geografia phisica; } \\
\text { Arithmetica; } \\
\text { Latim; Tradução de } \\
\text { períodos curtos de regência } \\
\text { grammatical; Francez, } \\
\text { traducção e exercício de } \\
\text { conversão; Inglez; grammatica } \\
\text { e tradução de pedaços. }\end{array}$ & 1860 \\
\hline $\begin{array}{l}\text { João Baptista Pereira de } \\
\text { Andrade; } \\
\text { José Machado Pinheiro Lima; } \\
\text { João da Costa Pinto Vianna; } \\
\text { Gabriel de Almeida Torres; } \\
\text { José de Almeida Torres; } \\
\text { José Joaquim Francisco Moura; } \\
\text { Felinto E. de Paula; } \\
\text { Assemiro Pompihia de Paula; } \\
\text { Irinês Vaz de Farias; } \\
\text { Frederico Augusto de S. } \\
\text { Nogueira; } \\
\text { Antonio de Freitas Saldanha; } \\
\text { João Pedro Schleder. }\end{array}$ & $\begin{array}{l}\text { Grammatica philosophica } \\
\text { Historia sagrada, no velho } \\
\text { testamento; } \\
\text { Grammatica Latina e traducção } \\
\text { de pedaços } \\
\text { Grammatica franceza, com } \\
\text { traducção em prosa }\end{array}$ & \\
\hline
\end{tabular}




\begin{tabular}{|l|l|c|}
\hline \multicolumn{1}{|c|}{ Aluno } & \multicolumn{1}{|c|}{ Exames da 5 classe } & Ano \\
\hline & $3^{\text {a }}$ classe & 1860 \\
\hline $\begin{array}{l}\text { Francisco Alves Guimarães; } \\
\text { Brasilio T. da Cunha }\end{array}$ & $\begin{array}{l}\text { Aulas: Francez, Geoghafia e } \\
\text { Historia, Aritmethica, Inglez e } \\
\text { Latim } \\
\text { Aulas: Geographia e História, } \\
\text { Francez }\end{array}$ & \\
\hline $\begin{array}{l}\text { Antonio de Freitas Saldanha } \\
\text { Irineu Vaz de Faria }\end{array}$ & Arithmetica & 1861 \\
\hline
\end{tabular}

FONTE: Livro: Atas de Exames de Alumnos do Lyceo (1858-1861)

Como se pode verificar pela lista dos examinados, eram Silveiras da Motta; Oliveiras Franco; Marcondes de Oliveira; Marques dos Santos; entre outras linhagens familiares cujos membros ocuparam cargos no poder executivo regional; nas secretarias de Estado; nas cadeiras de representação paranaense no poder legislativo - senadores, deputados gerais e federais, deputados estaduais, e um grande número de vereadores e outros cargos políticos locais ${ }^{5}$.

Geração que, vivendo os processos de urbanização das capitais do país, encontra no Paraná a preocupação em criar na capital da Província, nos anos de 1870, os "ares de uma capital civilizada", coerente com o ideário de modernidade que marcou a segunda metade do século XIX brasileiro.

Nesse sentido, a elite intelectual paranaense, que se propunha a "ilustrar" o país, a "libertar" a sociedade das velhas instituições religiosas e da ignorância, oriunda daquele estrato familiar, aposta, em nome da Ciência e das propostas republicanas, no restabelecimento do ensino secundário sob novas diretrizes curriculares e na criação de escolas normais.

No interior desse debate sobre o papel do ensino secundário verifica-se a presença dos saberes históricos que, criados com a cadeira de História Sagrada em 1858, caminham-se para a laicização de seus conteúdos no decorrer da década de 1860-1870. A discussão sobre a importância dos conhecimentos científicos, para os cursos secundários, irá marcar a disciplinarização desse saber no Paraná por intermédio do Instituto de Preparatórios. Nesse particular, reside um aspecto

5 Sobre a genealogia das classes dominantes e os cargos administrativos ocupados por membros dessas linhagens familiares ver: Oliveira (2001). 
singular no curso secundário no Paraná, se comparado ao que ocorria no colégio oficial da corte, que marcou a disciplinarização da História escolar.

O ensino no Liceu de Curitiba, submetido aos exames de preparatórios, funcionou de forma irregular devido à constante falta de professores e de alunos. Verifica-se que apenas as cadeiras de francês e de latim foram as que funcionaram com certa regularmente desde 1858 (TOLEDO, 2005). As dificuldades para o funcionamento do Liceu advinham, ainda, segundo as autoridades locais, das más condições de recursos financeiros, materiais e humanos, o que resultou na sua extinção em 07 de junho de $1869^{6}$.

Em meio a esse movimento de criação e extinção do curso secundário é que a disciplina de História vai se configurando no Paraná. Entre os elementos, que contribuíram para sua paulatina legitimação, identificaram-se: a presença da História nos exames de preparatórios; a afirmação da História como disciplina escolar autônoma da Geografia, no Colégio Pedro II; o crescimento da necessidade de um saber histórico da Pátria, que culminou com a criação da cadeira de História do Brasil em 1849 no colégio oficial da Corte.

No entanto, seu trajeto afirmativo no Paraná se apresenta marcado por maior destaque aos conteúdos da História Universal. Enquanto no colégio da corte a História nacional tornava-se objeto de intensas discussões entre os catedráticos $^{7}$ e assistia-se a um fortalecimento do campo historiográfico, com os estudos que se tornavam mais especializados, no Ginásio Paranaense a ênfase será a civilização, o processo civilizador europeu como eixo para entender a nova nação.

Em meio à intensificação da dualidade que caracterizava o ensino secundário na província do Paraná - o desejo expresso de criar um curso regular de humanidades e, ao mesmo tempo, oferecer as matérias que fossem exigidas nos exames, em forma de aulas avulsas - que é criada a cadeira de História e Geografia, por meio da Lei n.456 de 12 de Abril de 1876. Por intermédio de sua prescrição, a disciplina de História nasce unida a Geografia e compunha

6 Em 1869, foi extinto o Liceu, o curso ficou funcionando por intermédio de um Colégio Subvencionado, de propriedade do professor alemão Jacob Muller; com as cadeiras de francez e gramática portuguesa até 1871. Em 1871, o curso retorna a funcionar como Liceu até 1876, data da sua extinção como Liceu e da institucionalização do Instituto de Preparatórios e Escola Normal. (Ver: TOLEDO, 2005).

7 Uma ocorrência indicada por Gasparello (2004, p.149) ajuda a explicar essa afirmação. Trata-se do caso do professor Capistrano de Abreu que, no campo historiográfico, destaca-se pelo posicionamento quanto ao lugar de destaque que atribuía a Historia do Brasil. A autora registra que Capistrano foi posto em disponibilidade devido à sua inconformidade com as mudanças no plano de estudos do Colégio, que suprimira a cadeira de Historia do Brasil, da qual era catedrático. Essa ocorrência teria provocado intenso debate sobre a importância da História do Brasil como disciplina autônoma da História Universal. 
uma cadeira no Programa de Ensino do Instituto de Preparatórios e Escola Normal em 1876.

A legitimação da cadeira de História na instituição paranaense - então transformada de Liceu em Instituto de Preparatórios - se liga à adoção de duas obras didáticas que foram referências no colégio da corte: História Universal, do francês Victor Duruy, traduzido com adaptações para o ensino brasileiro; e, Lições de História do Brasil - para os alunos do Colégio Pedro II, de Joaquim Manoel de Macedo ${ }^{8}$.

Na circunstância social brasileira do século XIX, as marcas definidoras do desenvolvimento material e científico da humanidade, indicadas por Duruy, nortearam os conhecimentos da nacionalidade brasileira, conduzindo a produção da historiografia didática a se definir em duas frentes de saberes que se relacionavam mutuamente no ensino secundário: um saber Universal e um Nacional. Desse princípio, o ensino de História, por meio de suas cadeiras, realizou-se no Paraná, com o objetivo de formação e preparação de um grupo de intelectuais para ocupar cargos no quadro político e administrativo da sociedade que se pretendia "moderna" e "civilizada".

Porém, será no início do século XX que a disciplina se firma legitimamente na instituição paranaense com a atuação do lente Dario Persiano de Castro Vellozo. Ao tomar posição no plano da ação política e tentar responder, por meio de seus escritos e atuação na cadeira de História do Ginásio Paranaense, às questões locais com as quais se defrontava como membro da elite intelectual, Vellozo elaborou formas de entender o passado histórico da nação. Seu desempenho se traduziu em produção de imagens e de ações representativas da sociedade paranaense no período, no sentido de ajudá-la a compreender a ideia de nação que nascia com o projeto republicano.

Por outro lado, a ascensão e o privilégio que a disciplina de História incorporou nesse processo foram por suas ligações com a temática política. No Paraná, os ideais republicanos vão ser marcados por princípio comum da elite paranaense: a monarquia revelava "atraso", a república o "progresso". Tais representações de sociedade moderna estarão presentes na vida cultural e política de personalidades paranaenses como Emiliano Perneta, Emílio de Menezes, Rocha Pombo, Romário Martins, Victor do Amaral e, entre outros, Dario Persiano de Castro Vellozo. Ilustres representantes da intelectualidade paranaense do período, eles divulgam as novas de seu tempo em um período em que as famílias tradicionais ainda faziam valer seus interesses. República, povo, liberdade, patriotismo foram temas que permearam o universo intelec- 
tual desses agentes, não poucas vezes pensados de forma singular no contexto do pensamento intelectual e político brasileiro.

Verificam-se, no período de mais de vinte anos (1899-1920), que os caminhos da disciplina de História no Paraná seguiram seu próprio devir, pela ênfase dada aos problemas pedagógicos na instituição e os conteúdos da disciplina que receberam maior atenção. Ou seja, no Paraná, coube à cadeira de História Universal ligar o conteúdo nacional ao universal, com especial destaque a atuação do intelectual paranaense na afirmação da função social da História.

\section{O lugar do Paraná no Projeto Nacional: A disciplina de História no Ginásio Paranaense}

A mudança de regime vivida no país no final do século XIX não trouxe, em geral, mudanças significativas para as atividades educativas do ensino secundário no Paraná, nem a mudança de nome da instituição representou grandes transformações nos objetivos principais delegado a esse grau de ensino. Pelo Regulamento de 1891, o Instituto Paranaense passou a denominar-se Gymnasio Parananese, mantendo em anexo a Escola Normal, e seu funcionamento ainda atendia a Lei n.456 de 1876. Nesse sentido, os alunos do curso secundário dividiam o espaço físico com os do curso normal, bem como os professores e as mesmas aulas. (TOLEDO, 2005).

Essa configuração perdurou até 1920, quando o Decreto n.636 de 19 de maio de 1920 determinou a separação dos dois cursos. É dessa maneira que se pode dizer que a mudança de nome da instituição se fez muito mais porque os republicanos tinham como tarefa "sobrepor à representação do Império" (COSTA; SCHWARCZ, 2000).

$\mathrm{Na}$ esteira das continuidades, sua história é, em síntese, uma história de tentativa de equiparação ao Ginásio Nacional, nome que o Colégio Pedro II passou a ter com a Reforma Benjamin Constant e, posteriormente, voltou a denominar-se Colégio Pedro II. O artigo 27 do Regulamento de 1891 estipulava que o Programa das cadeiras seria modelado de acordo com o Ginásio Nacional do Rio de Janeiro, que se manteve como padrão para os demais ginásios do país.

Embora o curso no Ginásio Paranaense estivesse planejado para completarse no período de sete anos, sua realização ainda não era completa, uma vez que as aulas não foram ofertadas como previsto. As aulas de História, por sua vez, ocorriam. Nessa cadeira, a disciplina - que ficou prevista para ser ensinada no $6^{\circ}$ ano História Universal e $7^{\circ}$ ano a História do Brasil - foi se adequando aos 
novos contornos políticos e pedagógicos que se desenhavam no final do século XIX no país e às novas demandas disciplinares que conduziram o ensino de História à incorporação de novas abordagens e temas.

Com os ideais republicanos de construir uma sociedade representada pelo seu "povo", a vida intelectual de personagens paranaenses tornou-se um "fazer político" e aqueceu os debates em torno das ideias de liberdade, progresso, democracia e de cidadão no Paraná. Nesse sentido, nos primeiros tempos republicanos, parte da elite noticiava o seguinte no jornal $A$ República, endereçado ao "eleitorado paranaense":

Cumprindo um dever patriótico que nos é imposto pelas circunstâncias atuais do País, vimos à presença de nossos concidadãos, apresentar-lhes os nomes ${ }^{9}$ que julgamos corresponderem às necessidades do momento político da Nação e aos interesses superiores do Paraná. O pensamento político, único inspirado pelo patriotismo, é o que se concretiza numa ação comum e combina de todos os elementos nacionais para chegar-se ao fim glorioso da organização dos Estados Unidos do Brasil, sob a forma ampla da República Federativa. (A REPÚBLICA, 1888, p.1-2, apud TOLEDO, 2005, p.87)

A necessidade de um conhecimento mais apurado das nações, em um momento em que se procurava rediscutir a construção de uma identidade nacional, era bastante óbvia. Afinal, o significado de pátria, povo, liberdade, nação e cidadania - inscrito, no debate brasileiro, nos acontecimentos que marcaram a emergência do Brasil como corpo político autônomo - ganhava novos significados e abrangências à luz das tensões, conflitos e contradições, adensados fundamentalmente pela presença do ex-escravo e do imigrante, balizados com a mudança no projeto político das elites nacionais.

Porém, mais do que isso, a necessidade da História estava movida pelo interesse e importância que o ensino do passado passava a ter para se pensar a

9 São indicados: (Senadores) Dr. Ubaldino do Amaral Fontoura, advogado residente no rio de Janeiro; Dr. Generoso Marques dos Santos, advogado, residente em Curitiba; Dr. José Pereira dos Santos Andrade, comerciante, residente em Curitiba. (Deputados) Dr. Eduardo Mendes Gonçalves, engenheiro, residente em Curitiba; coronel Marciano Augusto Botelho Magalhães Lobo, militar, residente no Rio; major Bellarmino Augusto de Mendonça Lobo, engenheiro-militar, residente em Guarapuava; e Fernando Machado de Simas, farmacêutico, residente em Petrópolis; (Dicionário Histórico Biográfico do Estado do Paraná, 1991). 
identidade nacional, tendo como observatório a intensificação do povoamento no Paraná em início do século XX.

As mudanças na vida urbana no Paraná, trazidas pelas ações dos imigrantes, foram acompanhadas também pelas transformações tecnológicas na produção da erva-mate. As alterações tecnológicas nesse setor inauguraram um período em que o espaço urbano incorporou uma formação econômica industrializada. Nesse sentido, ele foi sendo (re)arranjado para alojar as novas construções, passando, a cidade, por uma expansão e reordenamento do traçado econômicocultural. No entanto, não era apenas crescimento cultural que Curitiba mostrava. No interior do processo, os problemas sociais se agravavam e as imagens de "progresso" escondiam ou entravam em contradição com o processo de urbanização crescente nos anos iniciais da República.

Esse conjunto de situação, trazido pelo crescimento urbano da capital, seria o espelho para a elite paranaense vislumbrar seu projeto de nação republicana e identidade nacional. Essa questão marcará, em boa medida, a redefinição da trajetória assumida pela disciplina no Paraná, cuja ênfase no estudo das civilizações é claro no documento oficial:

Na historia mencionar-se-ão, sem jamais descer a minudencias, os acontecimentos politicos, scientificos, litterarios e artisticos de cada época memoravel; serão expostas as causas que determinarão o progresso ou o estabelecimento da civilisação nos grandes periodos historicos, apreciados os homens que concorrem para as revoluções beneficas ou perniciosas da humanidade, mórmente os da America e sobretudo os do Brazil, agrupando-se em torno delles os factos caracteristicos das phases em que dominaram o espirito publico, devendo ser principal escopo do programma e do ensino, na historia patria particulamente instruir a historia educativa e vivificadora do sentimento nacional. (PARANÁ, Decreto de 1893, p.115-116, grifos meus).

Essa perspectiva foi adotada na instituição paranaense, embora estivessem separadas as cadeiras de História Universal e História do Brasil, a história nacional continuava sendo vista em uma perspectiva universalizante e, nessa nova orientação, internamente na História da América. Nessa nova orientação, o predomínio da História das Civilizações incorpora a História do Brasil por meio do estudo da América. Isso é verificado no excerto acima descrito, em que se percebe a manifestação dos conteúdos de História se definindo entre o saber 
universal e o nacional, e nos compêndios adotados pelo Ginásio Paranaense ${ }^{10}$ como apoio às Lições de História de Vellozo. (ACTAS DA CONGREGAÇÃO DO INTITUTO E ESCOLAR NORMAL (1876-1889) e ACTAS DA CONGREGAÇÃO DO GINASIO PARANAENSE E ESCOLA NORMAL (1889-1920).

Lócus da questão que vai mover as propostas para o ensino de História no Paraná, a história educativa do sentimento nacional será marcada pela atuação do lente Dario Persiano de Castro Vellozo, já referido, na cadeira de História no Ginásio Paranaense. Soma-se a isso, o fato de que, a partir do final do século XIX, várias possibilidades teóricas de se encaminhar o ensino de História no curso secundário vão surgir, não só pelo fato de que escrever uma outra História do Brasil fazia-se imprescindível com o fim do Império; mas também porque a História Universal recebe, com a sua expansão como saber científico, outras abordagens e temas, surgindo a ideia de História Geral e História das Civilizações no campo disciplinar. Isso trouxe mudanças para a historiografia e para o ofício do historiador no século seguinte.

Tais mudanças que se fizeram na história da disciplina serão sentidas com a atuação política e pedagógica de Vellozo, marcando um momento singular na história dessa disciplina se comparado ao que ocorria no colégio modelo ${ }^{11}$ nesse período.

No que se refere à mudança de perspectiva dos compêndios adotados, em 1898 é sugerido, pelos lentes e professores do Ginásio Paranaense e Escola Normal, o compêndio Lições de História Geral de Annibal Mascarenhas em substituição ao de Duruy e, em 1899, a História do Brasil, de Mattoso Maia, substitui Macedo. Enquanto no Colégio da Corte a História do Brasil de João Ribeiro marcaria, a partir de 1900, um terceiro momento na história dos livros didáticos no ensino secundário nacional, no Paraná o compêndio de Mattoso Maia continuaria sendo indicado para a cadeira de História do Brasil até, possivelmente, 1920. Isso porque, na sequência de 1898, em 1905, é sugerido: Lições de História, compêndio de História Universal, do paranaense Dario Persiano de Castro Velozzo - sendo que uma nova indicação de mudanças nos compêndios só vai ocorrer após a década de 1920, quando a Escola Normal passa por reforma e ocorre a separação física do Ginásio Paranaense.

10 Com o compêndio de Dario, foram adotados também em 1899: Revoluções Brasileiras de Gonzaga Duque e Curso de História dos Estados Americanos de João Manoel Pereira da Silva.

11 Sobre o ensino de História no Colégio Pedro II nesse período, Gasparello (2004) indica que é uma época em que a geração de historiadores buscava uma "renovação historiográfica nacional". Essa renovação foi percebida nos trabalhos de Capistrano de Abreu - no campo da historiografia acadêmica - e de João Ribeiro, no campo da historiografia didática. 
Em suma, no período inicial da República, no Colégio Pedro II, a cadeira de História do Brasil passava por mudanças significativas, discussões apaixonadas sobre sua especificidade e revisões temáticas, nas quais a formação do Brasil era um dos centros de discussão na historiografia didática. Principal problemática na obra de Ribeiro - a formação do Brasil -, o autor, para explicitar essa formação, "[...] liga os fios do litoral e do interior, apontando os agentes que constroem a história que chama comum e local" (GASPARELO, 2004, p.169). Sem grande expressão no Paraná, se comparada à ênfase (encontrada nos documentos) na atuação de Vellozo, os conteúdos da História do Brasil se firmam e recebem legitimidade institucional vinculada à História da América. O estudo da "civilização americana", entendida como expressão da nacionalidade brasileira na obra de Vellozo, aparece como eixo central em detrimento da história regional e nacional.

Embora do ponto de vista da composição da cadeira, o estudo da História do Brasil estivesse previsto para se realizar, em ambas as instituições, junto com a cadeira de História Universal, a ênfase, é preciso reafirmar, que João Ribeiro deu a história nacional no colégio da corte, a partir de 1900, não recebeu eco no Paraná ${ }^{12}$.

O compêndio do autor paranaense, Lições de História, foi publicado pela primeira vez em 1902. Informa DeNipotti (1998, p. 45) que a segunda edição foi de 1904 e a terceira de 1919, com reedições subsequentes em 1943, 1944, 1948 e 1949. O autor informa, ainda, que as três primeiras edições do compêndio traziam impressa a aprovação da Congregação do Ginásio Paranaense e Escola Normal.

A origem da obra, entretanto, foi anterior a 1902. Ela teve início em 1900 quando, em ata da Congregação de 16 de março, é nomeada uma comissão para "dar parecer a respeito da súmula da Historia Universal de Vellozo, que requereu auxílio para publicá-la. O Título da obra seria Lições de História Universal" (ACTA DA CONGREGAÇÃO, 16 de março de 1900, p.47-52). Três dias depois, a comissão apresentou seu parecer favorável a Vellozo, que, concluiu a súmula em 1898, a qual foi aprovada em 1900 e seria adotada nas aulas de História Universal por um período significativo de quase 20 anos. Opção, é preciso lembrar, não resultante apenas da relação que a obra apresentava com o ensino, mas da ligação que apresentava com o poder instituído, veiculado nas relações externa e internamente à instituição paranaense que ligavam o Paraná ao projeto nacional das elites brasileiras.

12 Em 1900 no Paraná a mocidade aprendia História do Brasil no compêndio de Matosso Maia. 
Esses elementos são os indícios que permitem afirmar que a disciplina de História no Ginásio Paranaense foi marcada pela atuação desse personagem que, juntamente com outras figuras regionais da época, denotou singularidade a constituição da História escolar no Paraná no período inicial da República brasileira.

\section{As Lições de História de Dario Vellozo}

História é o estudo da civilização através dos tempos.

(Dario Vellozo, 1948)

Lições é um compêndio de História Universal no qual os conteúdos são estruturados de forma a mostrar como, na história da humanidade, os homens foram passando de um estado primitivo e pré-histórico para um mais evoluído, constituindo-se de diferentes estágios de civilização. Em conformidade com a cronologia clássica, Vellozo divide a história em: pré-história, História Antiga; Idade Medieval e Tempos Modernos. Diz o autor no início de seu compêndio: "História é o estudo através dos tempos. Divide-se a História em: Antiga, Média e Moderna". (VELLOZO, 1948, p. 3). Por isso, as principais lições que compõem o livro estão divididas no tempo linear, que vai da Pré-história até a Modernidade, introduzindo, no decorrer da narrativa, acontecimentos sobre a América nessa história geral.

Voltada para os fatos políticos, é por meio das ações de grandes figuras humanas que vão se formando as grandes civilizações como a Grécia e Roma. Na cronologia desenvolvida por Vellozo, seria na Antiguidade clássica que estaria o exemplo mais acabado da constituição de uma vida política organizada nos moldes da "mais avançada civilização". Em sua compreensão, na Antiguidade encontrava-se o princípio de união como força do Império, encontrava-se ciência desenvolvida, regime de governo democrático e vida pública plena, até a morte do personagem principal dessa união.

Pretendia Alexandre reunir o Oriente ao Ocidente, estabelecendo império universal. Fundara 70 cidades; buscava difundir a língua grega; assimilava a civilização dos povos Orientais. Sábios 
gregos classificavam as plantas e os animais, e estudavam as regiões que o exército macedônio percorria. A morte veio cortar os projetos de Alexandre, desmembrou-se o império, repartidos pelos generais: a Ptolomeu coube o Egito; a Seleuco a Síria; a Lisímaco a Trácia. (VELLOZO, 1948, p. 44).

No aspecto da vida política, é ressaltado o papel dos "compatriotas" como fundamental para o desenvolvimento da Pátria, do sentimento de patriotismo e a construção de um centro político forte: "O espartano educa-se para a Pátria"; "O espartano apenas conhece uma carreira digna do cidadão: a das armas; não teme o inimigo, despreza a morte". (VELLOZO, 1948, p. 37, grifo meu). Em Atenas, o princípio cívico era o mesmo: "o povo exercia soberano influxo". A família tornou-se mais íntima; o casamento constituía a base da família; a criança recebia no lar bons exemplos e sadios ensinamentos; "os cidadãos trabalhavam pela dignificação da Pátria". (VELLOZO, 1948, p. 38 , grifo meu).

Roma também se tornou um grande império da Antiguidade porque "todo romano válido tomava armas na defesa da pátria”. (VELLOZO, 1948, p. 54). A decadência, por sua vez, ocorria por causa das rivalidades entre os povos, a guerra civil e o desmembramento do território pátrio. Ao relatar o declínio de Roma, anota: "De Cômodo a Diocleciano são guerras civis, é anarquia militar. Imperadores indignos sucedem-se arrastando o Império a todas as degradações. É a agonia". (VELLOZO, 1948, p. 61).

Com a "queda do feudalismo", uma nova era se instaura e a principal mudança que a memória do estudante deveria reter eram as novas relações sociais que, aos poucos, constituíam-se baseadas em novas leis e em um contrato social entre as classes:

Variavam os direitos dos burgueses; algumas cidades tinham obtido o de si mesma se governarem. Assim se estabeleciam as comunas. Os direitos da burguesia aumentavam á proporção que enfraquecia o poderio dos senhores. A comuna tem o direito de guerra [...]. Possue um selo para autenticar seus atos, [...] O conselho comunal reúne-se em edificio próprio. Há tribunal de justiça que julga os delitos e impõe penas. A comuna melhora a condição do servo que vai conseguindo carta de franquia; contribui para a formação do povo. (VELLOZO, 1948, $p$. 86-87, grifo теи). 
À frente, uma referência à formação do "povo" no desenvolvimento das cidades modernas e uma crítica à Monarquia:

O povo, que se formava, graças à liberdade que os antigos servos gozavam nos burgos, entra a sofrer a opressão e o despotismo, dos burgueses ricos. Este despotismo, intensificado no regime monárquico que lhe seguiu, congraçadas as duas nobrezas em causa comum, criou na plébe células de reação, que se foram propagando atravéz dos séculos e constituiram um dos fatores da grande revolução de 1789. (VELLOZO, 1948, p. 87).

Com especial enfoque na relação povo-liberdade, Vellozo explica de que lugar surgem as motivações históricas para o acontecimento de 1789 na França. Nesse traçado temporal, faz parte do período "Tempos Modernos" o movimento da Renascença e as Lutas Religiosas, onde ganha destaque e mais laudas o aspecto cultural e artístico desses eventos. No entanto, é a "Revolução Francesa", Lição XXXII, que se torna o grande marco do processo civilizatório da humanidade nesse período, visto que foi com ela que

A ciência expandia-se; ideais surgiram, libertários e generosos. O povo interessava-se, aplaudia, seguindo a nova corrente de opiniões, fator precioso de sua emancipação, de seus direitos. Esse intenso reagir contra os abusos do antigo regime, contra os prejuizos de classes, contra a suzerania; em pról do povo que sofria e tinha igual direito à vida, à liberdade, à civilização: chamou-se Revolução Francesa. (VELLOZO, 1948, p. 110, grifo meu).

Na narração dos acontecimentos de 1789, verifica-se a crítica à Monarquia e o favoritismo pela República como princípio político de Vellozo. Na passagem em que trata da ação de Napoleão I em 1804, transparece sua opção:

A república era extinta; mas, os ideais dos Enciclopedistas e as conquistas emancipadoras da Revolução se perpetuariam, constituindo inalienavel dote da Humanidade. As grandes reformas não 
foram anuladas, os direitos do homem entraram na constituição dos paises modernos. Foi o início da nova ordem social, a base da civilização do século XIX. (VELLOZO, 1948, p.112-113).

As lições terminam com informações sobre a América. Considerado a "aurora dos tempos modernos" o tema "Descobrimentos Marítimos" abre o período com a Lição XXVII. Nela, uma síntese de alguns fatos da História de Portugal é elaborada até chegar ao descobrimento da América e do Brasil, que também é tratado de forma sintética na Lição XXVII.

Na Lição XXXIV, as civilizações consideradas mais avançadas do continente são destacadas, entre elas a dos Incas é a indicada como a mais evoluída em civilização. Na sequência, critica a "exploração" que ocorre no continente americano pelos europeus, como por exemplo, a escravidão negra.

$\mathrm{Na}$ pequena passagem do texto que segue, nota-se o princípio da mestiçagem como constituição do "povo americano": "O cruzamento com os naturais estabeleceu-se aparecendo o mestiço, em cujas veias corria não raro o sangue europeu. A população das colônias crescia, em grande parte composta de mestiços." (VELLOZO, 1948, p.129, grifo meu).

À esse "povo mestiço" é atribuída a virtude da luta pela independência que se processou no século XVIII nas Américas. Diz o autor:

Os laços com as metrópoles afrouxavam, à proporção que novos elementos de vitalidade se formavam, e usos e costumes divergiam. Reações foram surgindo, a idéia de emancipação acentuou-se, proclamando as colônias a independência (VELLOZO, 1948, p.129).

Ao encerrar suas lições com o tema da "Independência", o caso Norte Americano é tratado com profunda admiração: "Washington, alma e cérebro da causa emancipadora, em um belo surto de entusiasmo e gratidão nacional, foi eleito, por unanimidade, primeiro presidente dos Estados Unidos, 1789”. (VELLOZO, 1948, p.132).

Quanto à independência sul-americana, poucas palavras resumem sua história. Em apenas uma página relata o acontecido: "à independência dos Estados Unidos, seguiu-se a emancipação da América Latina. A grande revolução francesa levara intensas vibrações a todos os povos que se orientavam, procu- 
rando fazer-se autônomos e livres". (VELLOZO, 1948, p. 133). E, a referência ao Brasil se faz nessa frase: "O Brasil, em 1822" (VELLOZO, 1948, p.133).

Vellozo integra o pensamento de republicanos que se esforçam para minimizar a distância entre o povo e a pátria; distância advinda, no seu entendimento, da própria formação histórica nacional. Este trajeto da história do país deveria, no entender do autor, ser estudado para compreender o próprio movimento "civilizatório" do povo brasileiro diante da história da humanidade. O fim pedagógico desse estudo seria levar a mocidade paranaense a relacionar a história nacional com as lições tiradas da Grécia e de Roma - quanto aos sentimentos de civilidade pátrios - e dos ideais das Revoluções Francesa e Norte Americana no tocante aos princípios de liberdade entre os povos.

Com Vellozo este esforço pedagógico se deu especialmente na criação de sentidos históricos para a República brasileira. Sentidos estes que são construídos nos princípios políticos mais gerais do contexto vivido pelo autor e parte da elite paranaense sobre o momento final do Império e nas suas perspectivas para as mudanças políticas que se processavam no país. Articuladas em seus sonhos, as repúblicas americanas teriam um marco final: enaltecimento da história universal patriótica, de cunho nacional, em detrimento de histórias regionais.

\section{Últimas considerações}

No processo instituidor do ensino secundário brasileiro, marcado pelo humanismo e a preparação de uma elite aos cursos superiores, a configuração do ensino de História no Paraná se realizou no decorrer do século XIX. Pela ação e discurso de intelectuais brasileiros, membros de uma elite política e intelectual, a história da nação foi construída por intermédio dos compêndios escolares. Produção historiográfica marcada pela dinâmica de conceitos como nação e pátria, verifica-se que a afirmação do campo disciplinar da História no Paraná fez-se por intermédio da obra de Dario Persiano de Castro Vellozo e sua atuação na instituição de ensino secundário paranaense. Seu compêndio Lições de História, adotado por duas décadas, resultou num artefato cultural por meio do qual as possibilidades e condições oferecidas para o conhecimento histórico, justificador do projeto de nação como unidade, se realizou no Paraná naquele momento.

As elites locais, diante dos acontecimentos político-culturais e econômicos vividos desde a Província em fins do século XIX - como a perspectiva de declínio de uma organização política fundada no paternalismo e no poder pessoal dos 
senhores locais, bem como a liberdade escrava e a intensificação da presença do imigrante europeu em terra paranaenses que marcou o início do século XX no Paraná - pensaram em um novo país, organizado segundo os moldes tomados por países da Europa - fundamentalmente a França - e os EUA.

Dario Vellozo, representativo de parte dessa elite local, ao tecer suas críticas ao passado, em geral extraídas dos ideais da Revolução Francesa e Norte-Americana, aponta a escravidão e a monarquia como símbolos maiores do "atraso" quando tenta criar "mitos fundadores" e símbolos republicanos para o passado da nação. Ao escrever seu compêndio de História, para ensinar lições à mocidade paranaense em um momento em que as noções e sentido de pátria, povo e liberdade estavam em pauta, redefiniu teoricamente os conteúdos de uma história a ser ensinada no Paraná diante das mudanças ocorridas em 1889.

Vellozo escreveu uma história patriótica, no novo sentido imprimido à palavra Pátria, ou seja, marcada pelo século que teve a liberdade como bandeira na América chamada "Latina". Em seu compêndio, a Nação parece não encontrar lugar preciso, como o sentido de Pátria. Ela é definida como lugar, por definição, da constituição da ação política do "povo", com ênfase na análise do caso francês, tendo a Revolução Francesa como princípio. A Nação está presente no autor como espaço universal que se realiza na luta política manifesta na pátria. $\mathrm{Ou}$ seja, apoia-se sobre o princípio de Nação que caracteriza o século XIX ${ }^{13}$, mas esse conceito recebe significativa carga de "sentimentos civis", quando tomada relativamente à ideia de Pátria cunhada por intelectuais anteriores. Constata-se que Vellozo enfatiza o patriotismo - o sentimento de pertença - não a Nação como território.

Com Vellozo, a disciplina de História no Paraná, no conjunto sóciocultural de sua formação disciplinar no Brasil, tratou de buscar na dimensão universal do ensino, por meio das Civilizações, o fio condutor para a exaltação do sentimento patriótico. Enfim, via na Pátria o próprio fundamento das nações civilizadas e, na ciência, na tolerância, na liberdade, no cidadão, a base de progresso dessa civilização. $\mathrm{O}$ verdadeiro dever patriótico consistia em fazer conhecer, amar e avivar o sentimento pela Pátria; a escola republicana seria exatamente um dos meios deste aprendizado e o ensino de História, ou o conhecimento do passado, o caminho mais apropriado para tal fim.

A relação entre ensino de História e formação do cidadão, no Paraná, encontrou nesse intelectual, que atuou ativamente no campo educacional para a formação das elites locais, uma concepção de História que permeou o universo político-cultural da sociedade paranaense no início do XX e marcou a singularidade da formação disciplinar no ensino secundário brasileiro. Isso porque,

13 Sobre esse tem ver, fundamentalmente, Hobsbawm (1990). 
enquanto na corte a diversidade regional também se tornava uma questão a ser enfrentada, do ponto de vista histórico, no propósito de anunciar a nova Nação; no Paraná localizam-se explicitamente indícios da relação ensino de História, Civismo e Civilização, numa concepção universal de identidade nacional; uma vez que Vellozo era representante das ideias de incorporação do "povo" à vida política da Nação, o que para ele era um conceito universal ligado à ideia de civilização, cujo modelo primário é a Antiguidade.

Deste estudo compreende-se que as elites brasileiras viveram em grande medida, como mostra o compêndio de Vellozo, com uma identidade nacional retirada da antiguidade, de onde formaram no decorrer do século XIX os modelos de democracia, liberdade e povo e, na continuidade, para pensar a recém implantada república brasileira, dialogaram com os acontecimentos da Revolução Francesa e Norte-Americana. Nesse trajeto, importa ao historiador do ensino sublinhar as diferentes propostas surgidas, em diferentes contextos, espaços e tempos, que determinaram a formação da historiografia acadêmica e da historiografia didática nacional. Trajeto que (re)coloca algumas questões cujas respostas nem sempre são consensuais entre os autores brasileiros como, por exemplo: para que serve ensinar história hoje?

\section{REFERÊNCIAS}

Fontes manuscritas

ATAS DO LICEU DE CURITIBA. Arquivo do Colégio Estadual do Paraná. Livro de Actas de Exames do Liceu. 1858-1861, Curitiba, [18-?].

ACTAS DA CONGREGAÇÃO DO INTITUTO E ESCOLAR NORMAL. Arquivo do Colégio Estadual do Paraná. Livro de Actas (1876-1889), Curirtiba, [18-?].

ACTAS DA CONGREGAÇÃO DO GINASIO PARANAENSE E ESCOLA NORMAL. Arquivo do Colégio Estadual do Paraná. Livro de Actas (18891920). Curitiba, [19-?].

Fontes impressas

BARROS, Bento Fernandes de. Relatório do Inspetor Geral da Instrução Publica. 29 de Dezembro de 1870. Curityba: Typ. C.M. Lopes, 1870. 
PARANÁ. Relatório do Presidente da Província Zacarias de Góes e Vasconcellos de 15 de julho de 1854.

. Decreto n. 6 de 17 de Fevereiro de 1893. In: Colleção de Leis, Decretos

e Regulamentos do Estado do Paraná, 1892-1893. Coritiba, Typ. Da República, 1894.

1991.

. Dicionário histórico-biográfico do Estado do Paraná. Curitiba: Chain,

VELLOZO, D.C. Lições de História. 6. ed. Curitiba: Instituto Neo-Pitagórico, 1948.

WESTPHALEN, C.M. Um Mazzolino de Fiori, vol. I.; vol. II. Curitiba: Imprensa Oficial; Secretaria de Estado da Ciência, Tecnologia e Ensino Superior, 2002.

Bibliografia

BITTENCOURT, C. M. Livro didático e conhecimento histórico: uma história do saber escolar. Tese (Doutorado) - Faculdade de Educação da Universidade de São Paulo, 1993.

COSTA, A. M. da; SCHWARCZ, L. M. 1890-1914. No tempo das certezas. São Paulo: Companhia das Letras, 2000.

DENIPOTI, C. A sedução da leitura: livros, leitores e história cultural. Paraná 1880-1930. Tese (Doutorado) - Universidade Federal do Paraná, Curitiba, 1998.

GASPARELLO, A. M. Construtores de Identidades: A pedagogia da nação nos livros didáticos da escola secundária brasileira. São Paulo: Iglu, 2004.

HAIDAR, M. L. M. O ensino secundário no império brasileiro. São Paulo: EDUSP/Grijalbo, 1972.

HOBSBAWM, H. Nações e nacionalismo desde 1870. São Paulo: Paz e Terra, 1990.

MOREIRA, J.E. Instalação e organização do Governo Provincial do Paraná. Boletim do Instituto Histórico, Geográfico e Etnográfico Paranaense, Curitiba, 1933. 
OLIVEIRA. R.C. O silêncio dos Vencedores. Genealogia, classe dominante e Estado do Paraná. Curitiba: Moinho do Verbo, 2001.

MATTOS, I. R. O tempo saquarema: a formação do estado imperial. 2. ed. São Paulo: Hucitec, 1987.

SILVA, G. B. Introdução crítica ao ensino secundário. Rio de Janeiro: MEC/ Cades, 1959.

TOLEDO, M. A. L. T. A disciplina de História no Paraná: os compêndios de História e a História ensinada (1876-1905). Tese (Doutorado). Programa de Pós Graduação em Educação: História, Política, Sociedade, Pontifícia Universidade Católica de São Paulo, 2005.

Texto recebido em 17 de dezembro de 2008.

Texto aprovado em 14 de janeiro de 2009. 